\title{
New Functions for Representing IEC 62305 Standard and Other Typical Lightning Stroke Currents
}

\author{
Vesna Javor $^{*}$ \\ Department of Theoretical Electrical Engineering, University of Nis, Faculty of Electronic Engineering, P.O. Box 73, \\ Aleksandra Medvedeva 14, 18000 Nis, Serbia
}

\begin{abstract}
New functions for approximating various lightning currents, either measured, assumed or generalized in the standard IEC 62305, are presented in this paper. The channel-base current function and its parameters, as well as analytical expressions of this function derivatives, integrals, and integral transformations are given. Parameters of new functions for representing first stroke currents, subsequent stroke currents, and long stroke currents from the standard IEC 62305 are calculated, so as of two-rise front function typical for experimentally measured first negative stroke currents. Results for lightning electric and magnetic field at different distances from the channel-base obtained by using the proposed function and the Modified transmission line model with exponential decay with height are in good agreement with the results from literature, but any other lightning stroke model can be used as well.
\end{abstract}

Keywords: Lightning discharge, first stroke current, subsequent stroke current, long stroke current, lightning electromagnetic field.

\section{INTRODUCTION}

Modeling of a lightning discharge is needed to estimate risk for people, animals and property, to take protection measures and avoid damages and failures in electrical and electronic circuits, installations and systems, various objects and structures within the lightning electromagnetic field (LEMF). There is also a constant need and public request to improve national and international standards in this area. The standard IEC 62305 [1] is treating general principles of lightning protection (Part 1), risk management (Part 2), physical damage and life hazard (Part 3), and protection of electrical and electronic systems within structures and services in LEMF (Part 4). Lightning current parameters are given in the Annex A of the Part 1, and current functions for analysis purposes in the Annex B. Generalized waveshapes and characteristics of the first positive, first and subsequent negative stroke currents, so as long stroke currents are presented in IEC 62305-1.

A few mathematical functions are given in literature for approximating lightning channel-base currents, either generally assumed [1], or directly measured during natural or artificially triggered lightning discharges, so to provide electric and magnetic fields at different distances from the channel-base as experimentally determined $[2,3]$.

The integral of the lightning channel-base current function predominantly influences the near LEMF, and integral of the square of that function determines Joules losses in conductors in cases of direct discharges. Current derivatives determine also amplitudes of induced currents

*Address correspondence to this author at the Department of Theoretical Electrical Engineering, University of Nis, Faculty of Electronic Engineering of Nis, P.O. Box 73, Aleksandra Medvedeva 14, 18000 Nis, Serbia;

Tel: +38118529105; Fax: +38118588399;

E-mail: vesna.javor@elfak.ni.ac.rs and voltages in electrical equipment and systems. Calculated far electric and magnetic field waveshapes approximately follow the waveshape of the channel-base current itself.

The choice of function parameters may be difficult depending on demands. The easier way is to select from literature and modify parameters so to represent a certain waveshape, but more general procedure is preferable. Besides, analytical solutions for the integral, derivative, and integral of the square of that function are very useful for time domain calculations, so as analytically determined Fourier transform for frequency domain calculations. Functions presented in this paper have these solutions together with not so complicated procedure to choose their parameters.

Various measured or assumed impulse waveshapes can be approximated using the new channel-base current (NCBC) function presented in the Section 2 of this paper. The influence of parameters on the function waveshape is also presented in the Section 2, as well as analytical expressions of its derivative, integrals, Laplace and Fourier transform. The parameters of this function are given for the first stroke currents from IEC 62305-1 in the Section 3, and for subsequent stroke currents in the Section 4. There is an overview of IEC 62305-1 standard lightning currents waveshapes and their parameters given in the Section 5. The long stroke current from the same standard is approximated by using the proposed LSC function, based on NCBC (Section 6). Double-peaked waveshapes, which are typical for experimentally measured natural first stroke currents, are approximated by using the two-rise front current function (TRF) with the same basic function as in NCBC (Section 7).

Heidler's function [4] is used in the IEC 62305-1, and its parameters are given in [1] and [5], for the first positive stroke current, first and subsequent negative stroke currents. Bewley earlier suggested the so-called biexponential i.e. double-exponential (DEXP) function [6]. Bruce and Golde used it not only for the first, but also for subsequent strokes 
[7]. The maximum current $I_{m}$, parameters $\alpha$ and $\beta$ determine the shape, convexity, rising time, decaying time, and other characteristics of the impulse. However, this function can not approximate the long-term current of the kA order. Although simple for analytical differentiation and integration, DEXP function has some disadvantages, such as non-realistic convex waveshape and too large first derivative at the zero time moment, which results in problems for LEMF calculations. Its parameters are not easy adjustable to various waveshapes of currents. The peak value of DEXP function is approximately, but not exactly equal to the chosen maximum current value.

Nucci and Rachidi [8] proposed the sum of two Heidler's functions for experimentally measured first stroke currents [2]. Nucci et al. [9] proposed the sum of Heidler's function and DEXP function as suitable for subsequent stroke currents. This function is recently often used in literature [10]. Diendorfer and Uman [11] determined the adequate parameters in the sum of two Heidler's functions to approximate subsequent stroke currents.

Feizhou and Shange [12] proposed one analytically integrable pulse function which needs the peak correction factor, so as Heidler's and DEXP functions, but is more complex for use than those two.

\section{NCBC FUNCTION}

NCBC function presented in this section is used for approximating various lightning stroke currents waveshapes and its analytically obtained derivative, integrals and integral transformations are useful for calculations of LEMF and induced effects in both time and frequency domain.

\subsection{NCBC Function and its Parameters}

NCBC function, proposed in [13] and [14], is given with the following expression

$$
i(t)= \begin{cases}I_{m}\left(t / t_{m}\right)^{a} \exp \left[a\left(1-t / t_{m}\right)\right], & 0 \leq t \leq t_{m}, \\ I_{m} \sum_{i=1}^{n} c_{i}\left(t / t_{m}\right)^{b_{i}} \exp \left[b_{i}\left(1-t / t_{m}\right)\right], & t_{m} \leq t \leq \infty,\end{cases}
$$

where $t_{m}$ is the rising time to the maximum current value $I_{m}$, whereas $a$ and $b_{i}$ are parameters of the function, $c_{i}$ the weighting coefficients so that $\Sigma c_{i}=1$, for $i=1, \ldots, n$, and $n$ is the number of expressions in the decaying part of the function. There is no need to include more than one term in the rising part of the function. However, the maximum current steepness, determined by parameter $a$ in the rising part, is an important quantity. For $n=1$ in (1) NCBC reduces to the simpler function denoted as $\mathrm{CBC}$ and used in this paper for representing IEC 62305-1 standard currents with an adequate choice of function parameters.

NCBC function has some advantages over $\mathrm{CBC}$ as it provides much better approximation of various decaying parts, thus resulting in more adequate LEMF waveshapes. It can be used in different engineering and electromagnetic models [10] of lightning discharges. It can also approximate DEXP function of given parameters [7], Heidler's function [5], or other based on it, so as functions from [9, 10], etc. The procedure to choose its parameters according to desired characteristics is given in [14]. Analytical derivative and integral of the function are needed for LEMF calculations in time domain [15], and its analytical Fourier and Laplace transforms [16] for LEMF calculations in frequency domain $[17,18]$.

NCBC function satisfies the condition of continuity, as well as its first derivative, and higher order derivatives are continuous except at the point of the maximum, for $t=t_{m}$. Thus, NCBC function is of differentiability class $\mathrm{C}^{1}$.

Rising part of the impulse function, for $n=1$, is shown in Fig. (1), in order to notice the characteristics of this shortduration part of the impulse and its steepness. This function is presented in the longer time interval in Fig. (2), as the decaying part of the impulse lasts much longer than the rising part. Waveforms in Figs. $(\mathbf{1}, \mathbf{2})$ correspond to the values of coefficients $a>1 \quad(a=4)$, and $b<1 \quad(b=0.03)$. Impulse starts at $t=0$ with the zero value and the first derivative of the function equal to zero, and by the time $t_{m}$ it reaches the maximum value $I_{m}$, after which it decreases tending to the zero value. If $a>1$ this function starts with a concave waveshape in the rising part having one saddle point and after that the convex part, thus rising up to the maximum (Fig. 1). For $0<a<1$ the rising part is just convex, which is physically non-realistic for lightning discharge currents.

The front current steepness is defined depending on the time needed in the front part to rise up to the value of $0.9 I_{m}$. Front rising time $t_{c}$ is usually determined so that a line is set through the points $\mathrm{A}\left(t_{a}, 0.3 I_{m}\right)$ and $\mathrm{B}\left(t_{b}, 0.9 I_{m}\right)$. It is the difference of time $t_{b}$, obtained for the point where this line crosses the horizontal line at $i / I_{m}=1$ and the time $t_{a}$, for the point where it crosses the $t$-axis (Fig. 1). It can be also defined as $t_{c}=t_{b},-t_{a}$, but for other two points, $\mathrm{C}\left(t_{a}, 0.1 I_{m}\right)$ and $\mathrm{B}\left(t_{b}, 0.9 I_{m}\right)$, as in [1].

The difference between the time moment $t_{k}$ when the current decreases to the half of its maximum value and previously mentioned $t_{a}$, is $t_{i}=t_{k}-t_{a}$, so called the time of the impulse duration (Fig. 2).

The exact value of the current peak can be chosen for NCBC function as desired, so as of the rising time $t_{m}$ to the peak value. Parameter $a$ in the rising part can be chosen independently from parameters $b_{i}$ and $c_{i}$ which are determining the decaying part of the function. This facilitates the procedure of approximating any arbitrary impulse function.

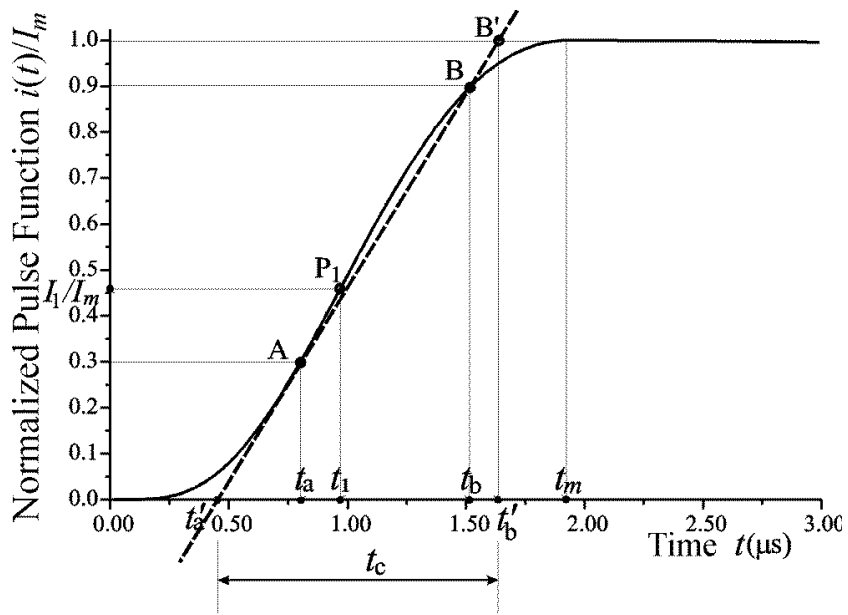

Fig. (1). Rising part of the normalized NCBC function. 


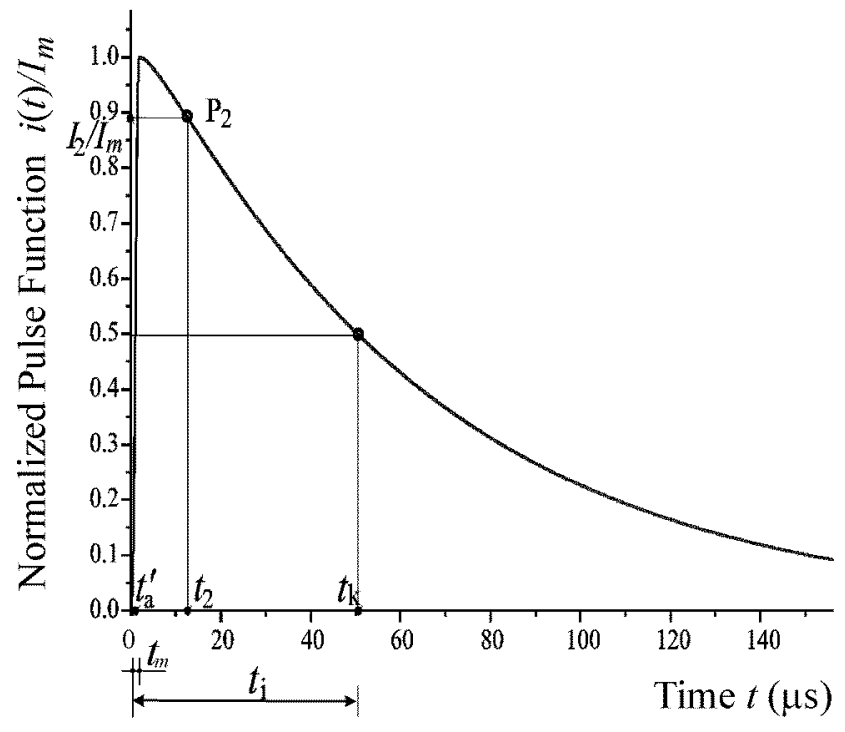

Fig. (2). Normalized NCBC function.

\subsection{The Derivative of NCBC Function}

The first derivative of $\mathrm{NCBC}$ function is calculated as

$$
\frac{\mathrm{d} i(t)}{\mathrm{d} t}= \begin{cases}I_{m} t_{m}^{-1} a\left(t / t_{m}\right)^{a-1}\left(1-t / t_{m}\right) \exp \left[a\left(1-t / t_{m}\right)\right], & 0 \leq t \leq t_{m}, \\ I_{m} t_{m}^{-1} \sum_{i=1}^{n} c_{i} b_{i}\left(t / t_{m}\right)^{b_{i}-1}\left(1-t / t_{m}\right) \exp \left[b_{i}\left(1-t / t_{m}\right)\right], & t \leq t_{m} \leq \infty .\end{cases}
$$

In some approximations of lightning currents the maximum current steepness is of greater interest than the waveshape itself. For NCBC function the value of the maximum current steepness in the rising part is calculated as

$$
\left.\frac{\mathrm{d} i(t)}{\mathrm{d} t}\right|_{\max }=I_{m} t_{m}^{-1} a^{0.5}\left(1-a^{-0.5}\right)^{a-1} \exp \left(a^{0.5}\right),
$$

and is obtained at $t=t_{m}\left(1-a^{-0.5}\right)$. It should be noticed from (3) that the maximum value of the first derivative is directly proportional to $I_{m}$ and inversely proportional to $t_{m}$. It can be adjusted to a chosen value, but there is a limit for given values of $I_{m}$ and $t_{m}$, if the saddle point is needed in the range $0<t_{\mathrm{P} 1}<0.316 t_{m}$, and if $a$ has to be greater than 1 (in order to provide the concave rising part in the beginning). For the saddle point in the range $0.316 t_{m}<t_{\mathrm{P} 1}<t_{m}$, the steepness can be greater, but for greater values of $a$.

NCBC function with calculated parameters $I_{m}=11 \mathrm{kA}$, $t_{m}=0.5826 \mu \mathrm{s}, a=0.5$ and $b=0.02$ well approximates DEXP function [7] having parameters $I_{m}=11 \mathrm{kA}, \alpha=3 \cdot 10^{4} \mathrm{~s}^{-1}$ and $\beta=10^{7} \mathrm{~s}^{-1}$ (which result in the rising time to the peak current $\left.t_{m}=0.5826 \mu \mathrm{s}\right)$. The decaying time to half of the peak value is about $23 \mu \mathrm{s}$ for both functions. The calculated exact peak value is $I_{\text {max }} \approx 10.78 \mathrm{kA}$ for DEXP function which can simply be chosen for NCBC also.

The derivative of NCBC current (2) in the first $1 \mu \mathrm{s}$ is presented in Fig. (3) for different values of $a$, for the maximum current $I_{m}=13 \mathrm{kA}$ and $t_{m}=0.5 \mu \mathrm{s}$, so as for the values $I_{m}=11 \mathrm{kA}$ and $t_{m}=0.5826 \mu \mathrm{s}$.
For $0<a<1$ values of the first derivative are very large, so $\mathrm{d} i / \mathrm{d} t \rightarrow \infty$ at the time $t=0^{+}$, as presented in [15]. For $a=1$, $I_{m}=13 \mathrm{kA}$ and $t_{m}=0.5 \mu \mathrm{s}$, the maximum current steepness is $\left.(\mathrm{d} i / \mathrm{d} t)\right|_{\max } \approx 70.7 \mathrm{kA} / \mu \mathrm{s}$ at $t=0^{+}$and the current function starts with a linear rise. Its first derivative decreases to zero value up to $t=t_{m}$ (Fig. 3) and after that has negative values.

The saddle point $\mathrm{P}_{1}$ (Fig. 1) moves to the right as the parameter $a$ increases, but the maximum value of the current first derivative decreases to its minimum positive value at $a=2.14$. This is determined for the zero value of the second derivative with respect to variable $a$. As $a$ increases starting from this value the maximum of the first derivative also increases, but the saddle point moves from $t=0.316 t_{m}$ to the right of the timeline towards $t_{m}$. This can be used if larger current steepness values are needed. E.g. for $I_{m}=11 \mathrm{kA}$ and $t_{m}=0.5826 \mu \mathrm{s}$ the obtained maximum current derivative is $\left.(\mathrm{d} i / \mathrm{d} t)\right|_{\max } \approx 105 \mathrm{kA} / \mu \mathrm{s}$, as for Heidler's function in [5], for the value of parameter $a=71$.

For different values of $a$, LEMF waveshapes differ just in a short time interval at the beginning of the rising part. In order to have a saddle point in the rising part e.g. in the range $0<t_{\mathrm{P} 1}<0.25 t_{m}$, parameter $a$ has to be $1<a<2$, which gives smaller current steepness but still gives good results for LEMF at different distances. Besides, it should be noted that smaller values of current steepness given in literature correspond to experimental results for natural lightning discharges, whereas higher values correspond to artificially initiated discharges of the same type.

In the range $1 \leq a \leq 2.14$ the maximum current steepness is achieved for $a \rightarrow 1$. Thus, for $a=1, I_{m}=13 \mathrm{kA}$ and $t_{m}=0.5 \mu \mathrm{s}$ its value is $\left.(\mathrm{d} i / \mathrm{d} t)\right|_{\max }=\mathrm{e} I_{m} t_{m}{ }^{-1} \approx 70.7 \mathrm{kA} / \mu \mathrm{s}$, for $I_{m}=11 \mathrm{kA}$ and $t_{m}=0.5826 \mu \mathrm{s}$ is $\left.(\mathrm{d} i / \mathrm{d} t)\right|_{\max } \approx 51.3 \mathrm{kA} / \mu \mathrm{s}$, whereas for $a=1.1$ and the concave to convex rising part of the current, for $I_{m}=13 \mathrm{kA}$ and $t_{m}=0.5 \mu \mathrm{s}$ its value is $\left.(\mathrm{d} i / \mathrm{d} t)\right|_{\max } \approx 57.3 \mathrm{kA} / \mu \mathrm{s}$, and for parameters $I_{m}=11 \mathrm{kA}$ and $t_{m}=0.5826 \mu \mathrm{s}$ is $\left.(\mathrm{d} i / \mathrm{d} t)\right|_{\max } \approx$

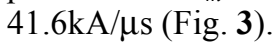

The influence of parameter $a$ on the waveshape of the rising part of NCBC function is presented in Fig. (4).

In the decaying part the minimum of the current derivative depends on $b_{i}$ and $c_{i}$, and is obtained as

$$
\left.\frac{\mathrm{d} i(t)}{\mathrm{d} t}\right|_{\min }=-I_{m} t_{m}^{-1} \sum_{i=1}^{n} c_{i} b_{i}^{0.5}\left(1+b_{i}^{-0.5}\right)^{b_{i}-1} \exp \left(-b_{i}^{0.5}\right) \text {. }
$$

Parameters $b_{i}$ and weighting coefficients $c_{i}$ determine the function waveshape in the decaying part. Thus, they influence predominantly on the integral of the current, so if experimentally obtained, it can be achieved with a suitable choice of these parameters. For $n=1, a=1.5$ and $t_{m}=1.9 \mu \mathrm{s}$, the influence of parameter $b$ on the waveshape of the decaying part is presented in Fig. (5), for $0.01 \leq b \leq 0.1$.

For parameters $a=1.5$ and $b=0.01$, the influence of $t_{m}$ on the decaying part of the function is shown in Fig. (6), for $0.5 \mu \mathrm{s} \leq t_{m} \leq 10 \mu \mathrm{s}$.

Parameters of NCBC function approximating the often used function from [9] based on [2], for the same selected 
value of the maximum current $I_{m}=11 \mathrm{kA}$ and the rising time to that value $t_{m}=0.472 \mu \mathrm{s}$, are determined (for $n=2$ ) as $a=1.1$, $b_{1}=0.16, c_{1}=0.34, b_{2}=0.0047$ and $c_{2}=0.66$.

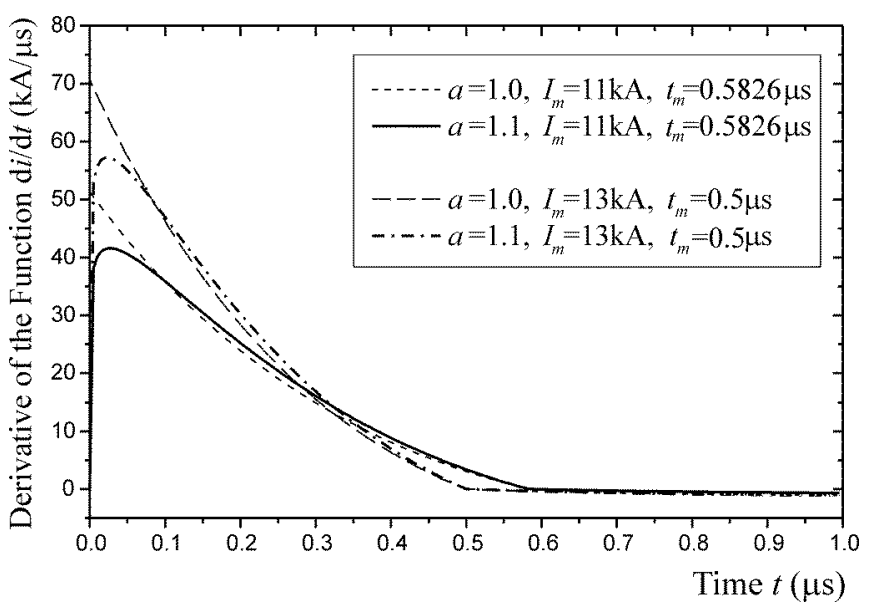

Fig. (3). First derivative of NCBC function in the first $1 \mu$ s.

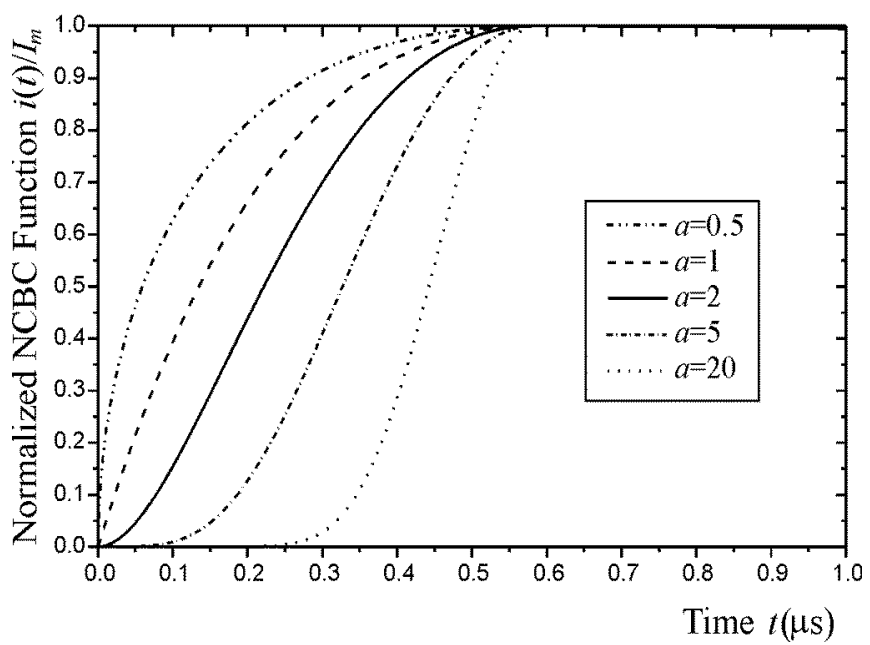

Fig. (4). Normalized NCBC function in the first $1 \mu \mathrm{s}$ for $b=0.03$, $t_{m}=0.5826 \mu \mathrm{s}$ and for different values of parameter $a$.

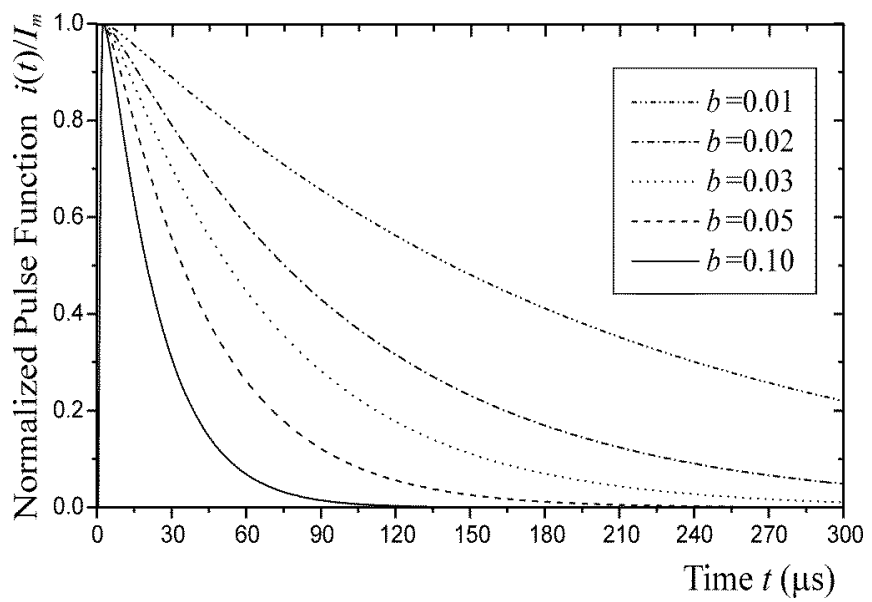

Fig. (5). Normalized NCBC function for $a=1.5, t_{m}=1.9 \mu \mathrm{s}$ and different values of parameter $b$.
Electric and magnetic field results for both these functions at different distances from the channel-base, obtained by using Modified transmission line model with exponential decay with height (MTLE) as an engineering model of a lightning return stroke, are in very good agreement [19]. Any other engineering or electromagnetic model for lightning stroke modeling can imply the presented NCBC function as well.

\subsection{Integrals of NCBC Function}

The analytical expression for the integral of NCBC function is

$$
\int_{0}^{t} i(t) \mathrm{d} t= \begin{cases}\frac{I_{m} t_{m} \exp (a)}{a^{a+1}} \gamma\left(a+1, a t / t_{m}\right), & 0 \leq t \leq t_{m}, \\ I_{m} t_{m}\left\{\frac{\exp (a)}{a^{a+1}} \gamma(a+1, a)+\right. & \\ \left.\sum_{i=1}^{n} c_{i} \frac{\exp \left(b_{i}\right)}{b_{i}^{b_{i}+1}}\left[\gamma\left(b_{i}+1, b_{i} t / t_{m}\right)-\gamma\left(b_{i}+1, b_{i}\right)\right]\right\}, t_{m} \leq t \leq \infty,\end{cases}
$$

for $\gamma(a+1, x)=\int_{0}^{x} t^{a} \exp (-t) \mathrm{d} t$ the incomplete Gamma function (Euler function of the second kind).

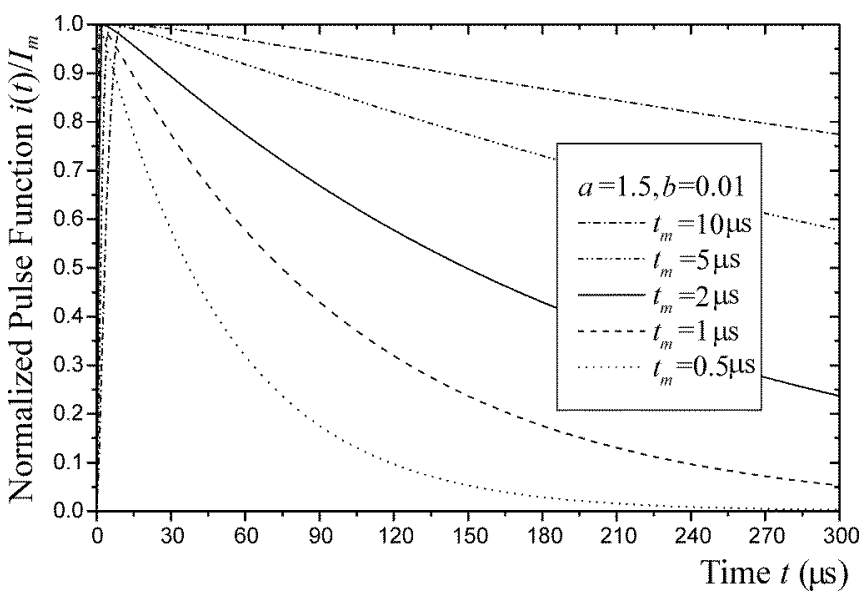

Fig. (6). Normalized NCBC function for $a=1.5, b=0.01$ and different values of $t_{m}$.

The analytical integral of NCBC function for a subsequent negative stroke current $0.25 / 100 \mu \mathrm{s}$, as given in [1], and the corresponding integral of Heidler's function [20] are compared in Fig. (7). The results are given for the integral of Heidler's function having parameters $n=10, \tau_{1}=0.454 \mu \mathrm{s}, \tau_{2}=$ $143 \mu \mathrm{s}, \eta=0.993$, and $I_{0}=25 \mathrm{kA}$ for the lightning protection level LPL III-IV [1]. The adequate NCBC function has parameters $n=1, t_{m}=0.65 \mu \mathrm{s}, a=20, b=0.00467$, and $I_{m}=25.2 \mathrm{kA}$ for LPL III-IV.

Integral of the square of NCBC function determines Joules losses in a conductor having resistance $R$, subjected to the flow of a lightning pulse current. In such a case the specific energy is calculated as Joules losses per unit resistance 


$$
\begin{aligned}
& W(t) / R=\int_{0}^{t} i^{2}(0, t) \mathrm{d} t= \\
& \int I_{m}^{2} t_{m} \frac{\exp (2 a)}{(2 a)^{2 a+1}} \gamma\left(2 a+1,2 a t / t_{m}\right), \quad 0 \leq t \leq t_{m}, \\
& I_{m}^{2} t_{m}\left\{\frac{\exp (2 a)}{(2 a)^{2 a+1}} \gamma(2 a+1,2 a)+\right. \\
& =\left\{\sum_{i=1}^{n} c_{i}^{2} \frac{\exp \left(2 b_{i}\right)}{\left(2 b_{i}\right)^{2 b_{i}+1}}\left[\gamma\left(2 b_{i}+1,2 b_{i} t / t_{m}\right)-\gamma\left(2 b_{i}+1,2 b_{i}\right)\right]+\right. \\
& 2 \sum_{\substack{j, k=1 \\
j \neq k}}^{n} c_{j} c_{k} \frac{\exp \left(b_{j}+b_{k}\right)}{\left(b_{j}+b_{k}\right)^{b_{j}+b_{k}+1}}\left[\gamma\left(b_{j}+b_{k}+1,\left(b_{j}+b_{k}\right) t / t_{m}\right)-\right. \\
& \left.\left.\gamma\left(b_{j}+b_{k}+1, b_{j}+b_{k}\right)\right]\right\} \text {, } \\
& t_{m} \leq t<\infty,
\end{aligned}
$$

for the incomplete Gamma function (Euler function of the second kind) $\gamma(a+1, x)=\int_{0}^{x} t^{a} \exp (-t) \mathrm{d} t$.

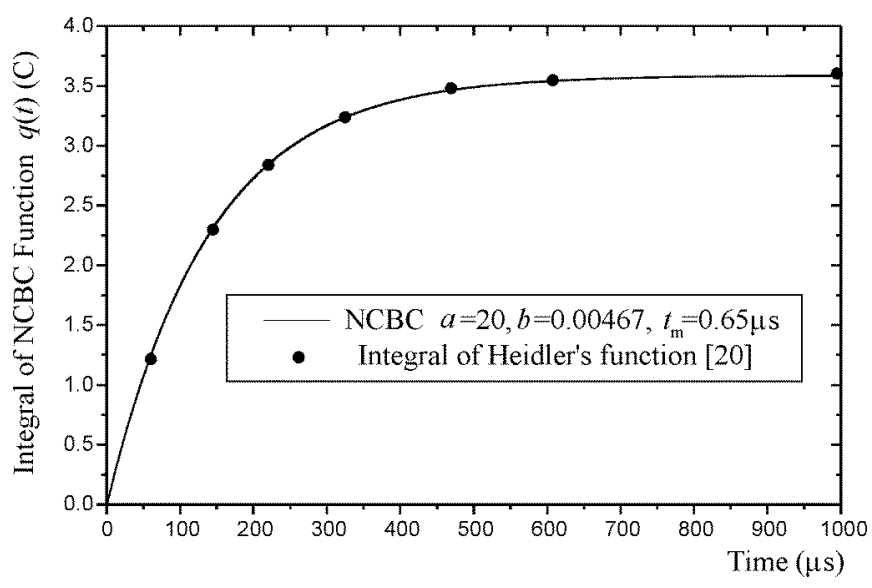

Fig. (7). Integral of NCBC [19] and Heidler's function [20] for the subsequent negative stroke $0.25 / 100 \mu$ s [1] and LPL III-IV.

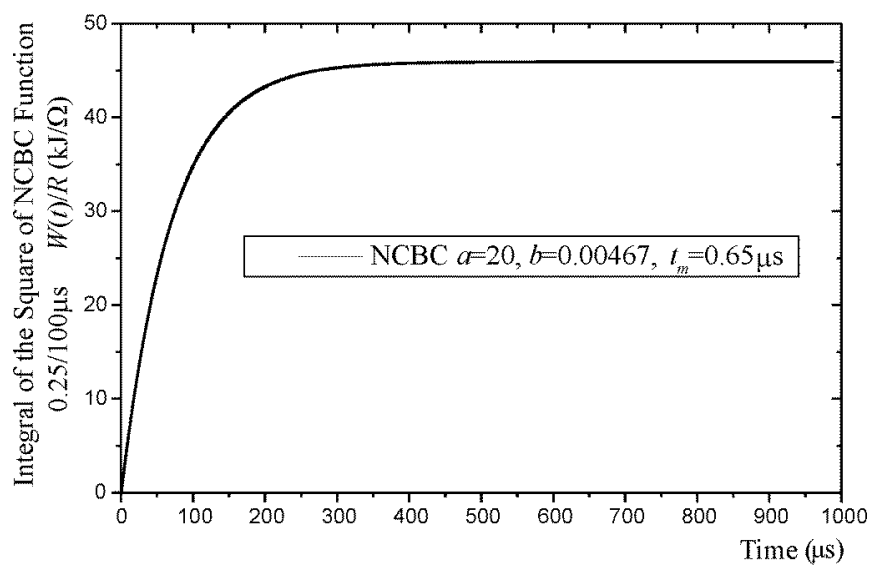

Fig. (8). Integral of the square of NCBC function for the subsequent negative stroke $0.25 / 100 \mu$ s [1] and LPL III-IV.
Integral of the square of NCBC function for parameters $n=1, I_{m}=25.2 \mathrm{kA}, t_{m}=0.65 \mu \mathrm{s}, a=20$ and $b=0.00467$, adequate to IEC 62305-1 subsequent negative stroke current $0.25 / 100 \mu$ s [1] for LPL III-IV, is presented in Fig. (8). Such analytical calculations would be much more complicated with most of channel-base functions usually used in literature.

For the impulse charge of the first positive stroke current and LPL I for Heidler's function of parameters $n=10$, $\tau_{1}=19 \mu \mathrm{s}, \tau_{2}=485 \mu \mathrm{s}, \eta=0.93$ and $I_{0}=200 \mathrm{kA}$ in [1] is given the value $\int_{0}^{\infty} i(t) \mathrm{d} t=100 \mathrm{C}$, which is obtained also from (5) for NCBC function of parameters $t_{m}=26 \mu \mathrm{s}, a=20, b=0.0665$, and $I_{m}=200 \mathrm{kA} / 0.93$. For the integral of the square of that NCBC function is obtained $\int_{0}^{\infty} i^{2}(t) \mathrm{d} t \cong 12 \mathrm{MJ} / \Omega$ from (6), whereas for Heidler's function the approximate expression gives value of $10 \mathrm{MJ} / \Omega$ which represents the specific energy as defined in [1] for the first positive stroke current and LPL I.

\subsection{Fourier Transform of NCBC Function}

Laplace and Fourier transform of NCBC function can be determined analytically. Fourier transform is needed in order to perform the calculation of LEMF in the frequency domain in the case of a lossy ground.

$$
\begin{aligned}
& \underline{I}(f)=\frac{I_{m} t_{m} \exp (a)}{\left(a+\mathrm{j} 2 \pi f t_{m}\right)^{a+1}} \gamma\left(a+1, a+\mathrm{j} 2 \pi f t_{m}\right)+ \\
& I_{m} t_{m} \sum_{i=1}^{n} c_{i} \frac{\exp \left(b_{i}\right)}{\left(b_{i}+\mathrm{j} 2 \pi f t_{m}\right)^{b_{i}+1}} \Gamma\left(b_{i}+1, b_{i}+\mathrm{j} 2 \pi f t_{m}\right),
\end{aligned}
$$

for $\gamma(a+1, x)=\int_{0}^{x} t^{a} \exp (-t) \mathrm{d} t$ and

$\Gamma(a+1, x)=\int_{x}^{\infty} t^{a} \exp (-t) \mathrm{d} t$.

\section{CBC FUNCTION PARAMETERS FOR THE STANDARD IEC 62305-1 FIRST STROKE CURRENTS}

For the first positive stroke current, according to IEC $62305-1$ standard pulse function $10 / 350 \mu \mathrm{s}$, and the corresponding Heidler's function parameters given in [1] and [5], the following parameters of the normalized $\mathrm{CBC}$ function $i(t) / I_{m}$ are obtained: $a=20, b=0.0665$ and $t_{m}=26 \mu \mathrm{s}$.

The function waveshape in the first $40 \mu \mathrm{s}$ is presented in Fig. (9), with the rising time $T_{1}=10 \mu$ s from $0.1 I_{m}$ to $0.9 I_{m}$. The decaying time to $0.5 I_{m}$ (half of the peak value) is $T_{2}=350 \mu \mathrm{s}$ (Fig. 10), as in [1].

For $I_{m}=200 \mathrm{kA}$, and the lightning protection level LPL I, the maximum current derivative obtained analytically for $\mathrm{CBC}$ is $\left.(\mathrm{d} i / \mathrm{d} t)\right|_{\max } \approx 24.6 \mathrm{kA} / \mu \mathrm{s}$ and for Heidler's function $28.2 \mathrm{kA} / \mu \mathrm{s}$ according to approximate expression given in [5].

For the first negative stroke current according to IEC $62305-1$ standard current function $1 / 200 \mu \mathrm{s}$ and the corresponding Heidler's function of parameters given in [1] and [5], the following parameters of the normalized CBC 
function $i(t) / I_{m}$ are obtained: $a=20, b=0.0096$ and $t_{m}=2.6 \mu \mathrm{s}$. The function shape in the first $6 \mu \mathrm{s}$ is presented in Fig. (11), with the rising time $T_{1}=1 \mu \mathrm{s}$ from $0.1 I_{m}$ to $0.9 I_{m}$. The decaying time to $0.5 I_{m}$ (half of the peak value) is $T_{2}=200 \mu \mathrm{s}$ (Fig. 12), as given in [1].

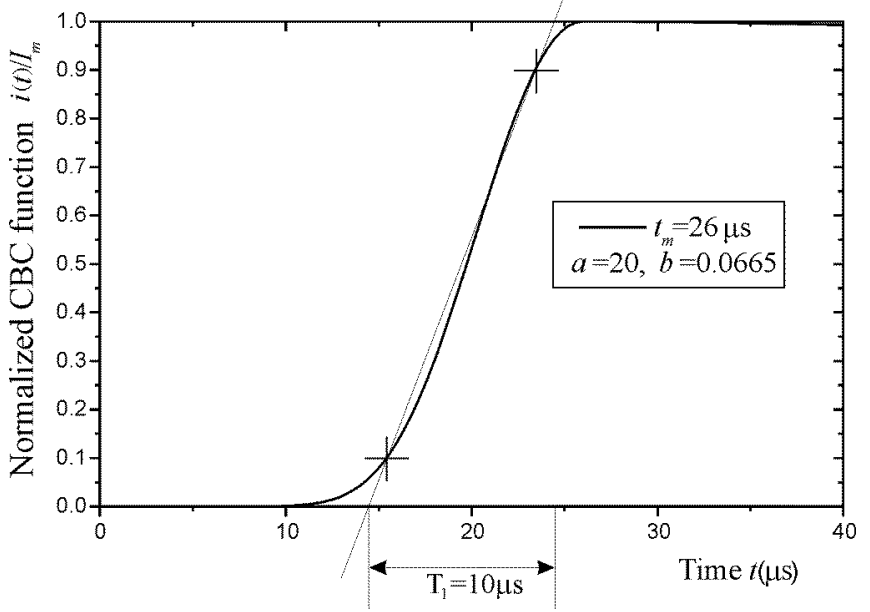

Fig. (9). Rising part of the first positive stroke current $10 / 350 \mu$ s.

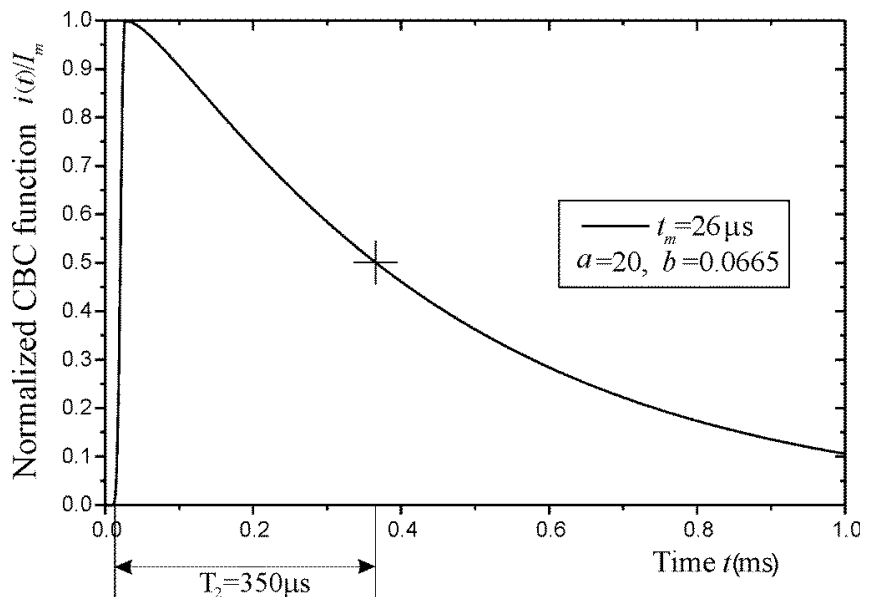

Fig. (10). Decaying part of the first positive stroke current $10 / 350 \mu \mathrm{s}$.

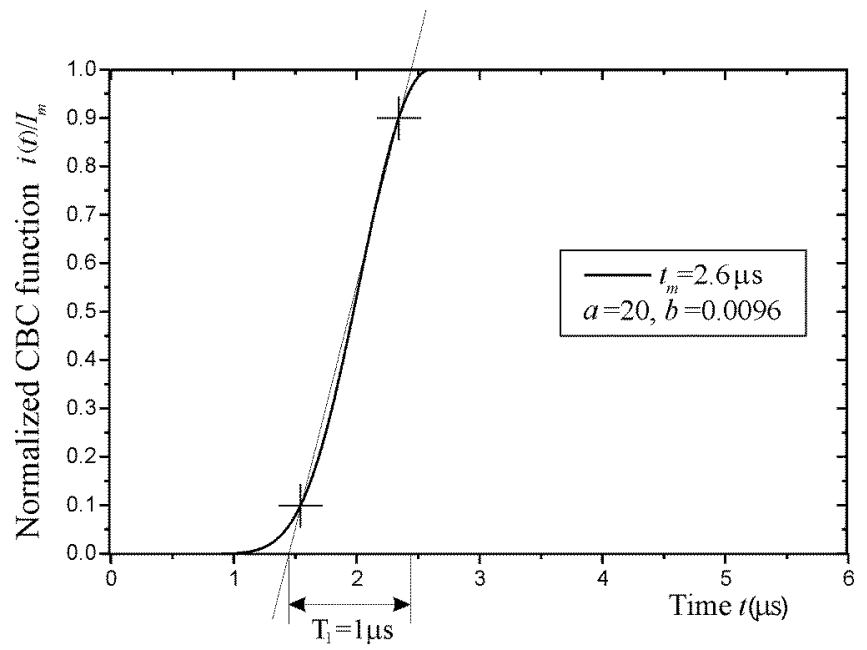

Fig. (11). Rising part of the first negative stroke current $1 / 200 \mu \mathrm{s}$.

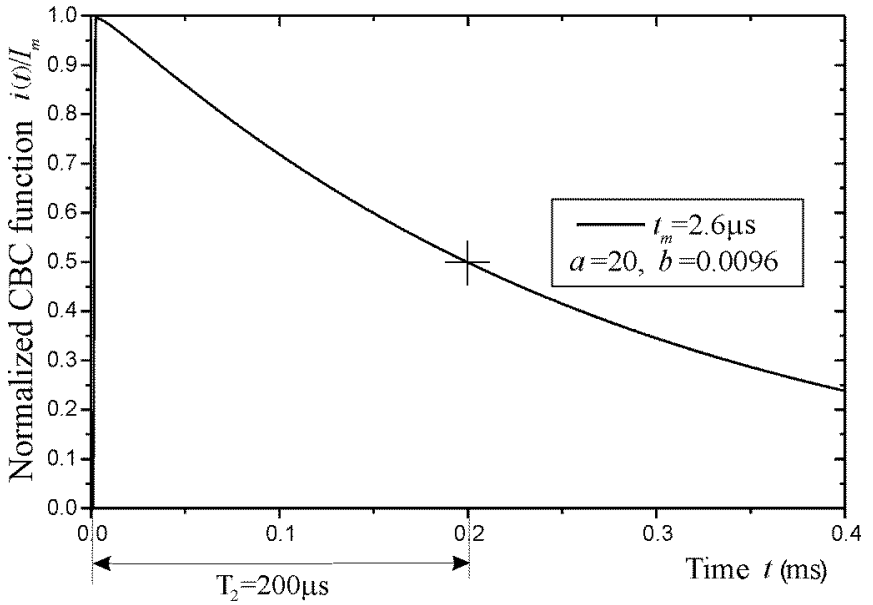

Fig. (12). Decaying part of the first negative stroke current $1 / 200 \mu$ s.

\section{CBC FUNCTION PARAMETERS FOR THE STANDARD IEC 62305-1 SUBSEQUENT STROKE CURRENTS}

For a subsequent negative stroke and corresponding current waveshape $0.25 / 100 \mu \mathrm{s}$, as given in [1] and [5], the parameters of the normalized $\mathrm{CBC}$ function are calculated as $a=20, b=0.00467$ and $t_{m}=0.65 \mu \mathrm{s}$.

The function waveshape in the first $1.6 \mu \mathrm{s}$ is given in Fig. (13), with the rising time $T_{1}=0.25 \mu$ s from $0.1 I_{m}$ to $0.9 I_{m}$. The decaying time from $I_{m}$ to $0.5 I_{m}$ is $T_{2}=100 \mu \mathrm{s}$ (Fig. 14). The obtained maximum of the first derivative for $I_{m}=50 \mathrm{kA}$ (LPL I for the subsequent negative stroke) of this $\mathrm{CBC}$ function is approximately $246 \mathrm{kA} / \mu \mathrm{s}$. It is ten times greater than for the first positive stroke current, so as in the case of using Heidler's function $(282 \mathrm{kA} / \mu \mathrm{s})$. There is a remark in [5] that such current steepness can not be achieved by DEXP function.

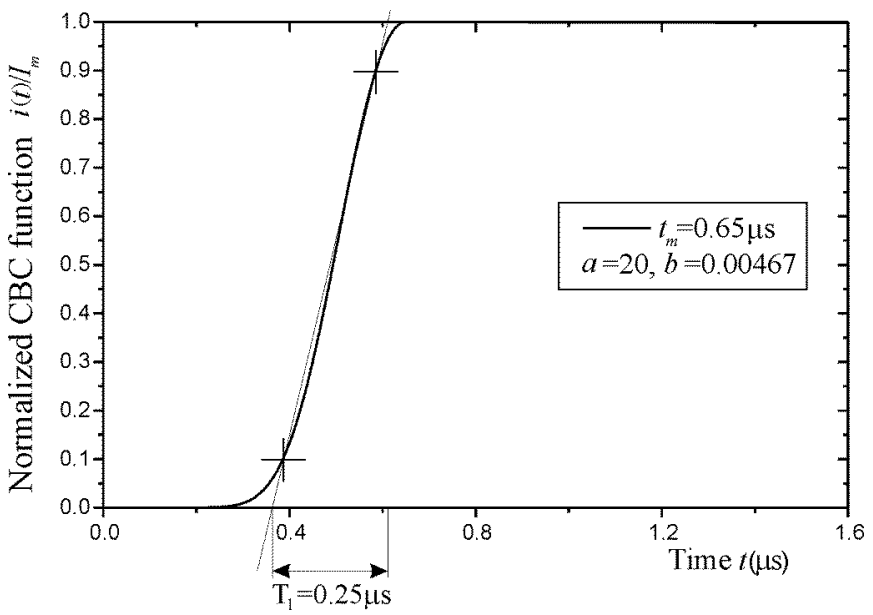

Fig. (13). Rising part of the subsequent negative stroke current $0.25 / 100 \mu \mathrm{s}$.

The parameters of $\mathrm{CBC}$ function are the same regardless of the level of lightning protection. The correction factor is not needed for $\mathrm{CBC}$ function, so any maximum current value can be simply obtained by multiplying the normalized $\mathrm{CBC}$ function with the corresponding peak current value. 


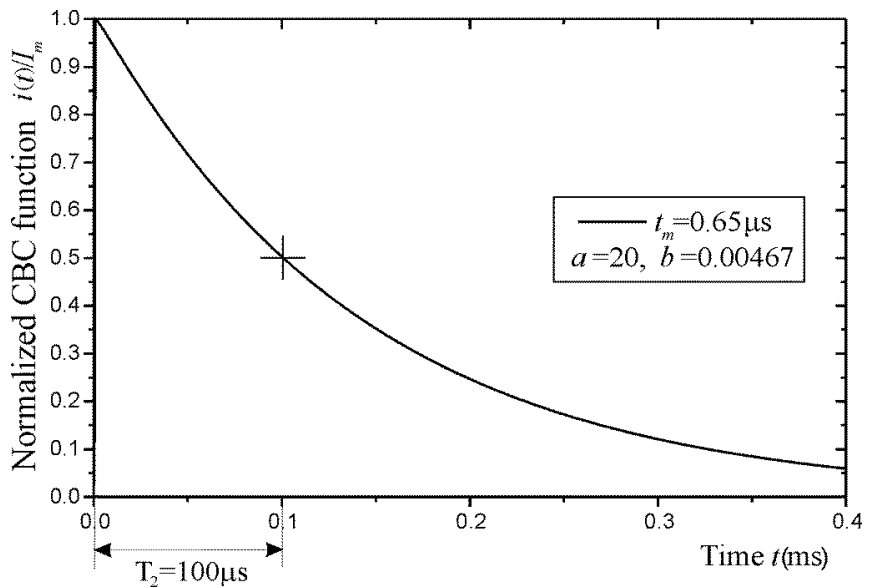

Fig. (14). Decaying part of the subsequent negative stroke current $0.25 / 100 \mu \mathrm{s}$.

\section{CBC FUNCTION PARAMETERS FOR THE STANDARD IEC 62305-1 LIGHTNING CURRENTS}

Parameters of Heidler's function from IEC 62305-1 for generalized waveshapes of the first positive, first and subsequent negative stroke currents are presented in the Table 1 and the corresponding $\mathrm{CBC}$ function parameters in the Table 2. For Heidler's function peak values are $I(\mathrm{kA}) / \eta$, so these are taken in the Table 2 for the corresponding peak values $I(\mathrm{kA})$ of CBC function for different LPL-s. However, peak values $I(\mathrm{kA})$ from the Table 1 can be also taken for $\mathrm{CBC}$ function as more suitable for generalized waveshapes, and for all other parameters the same as in the Table 2.

Table 1. Parameters of Heidler's Function from the Standard IEC 62305-1 [1]

\begin{tabular}{|c|c|c|c|}
\hline \multicolumn{4}{|c|}{ Heidler's Function Parameters } \\
\hline & $\begin{array}{c}\text { First Positive } \\
\text { Stroke } \\
10 / 350 \mu \mathrm{s}\end{array}$ & $\begin{array}{c}\text { First Negative } \\
\text { Stroke } \\
1 / 200 \mu \mathrm{s}\end{array}$ & $\begin{array}{c}\text { Subsequent } \\
\text { Negative Stroke } \\
0.25 / 100 \mu \mathrm{s}\end{array}$ \\
\hline$I(\mathrm{kA})$ & $\begin{array}{c}200 \text { (LPL I) } \\
150 \text { (LPL II) } \\
100 \text { (LPL III-IV) }\end{array}$ & $\begin{array}{c}100 \text { (LPL I) } \\
75 \text { (LPL II) } \\
50 \text { (LPL III-IV) }\end{array}$ & $\begin{array}{c}50 \text { (LPL I) } \\
37.5 \text { (LPL II) } \\
25 \text { (LPL III-IV) }\end{array}$ \\
\hline$n$ & 10 & 10 & 10 \\
\hline$\eta$ & 0.93 & 0.986 & 0.993 \\
\hline$\tau_{1}(\mu \mathrm{s})$ & 19 & 1.82 & 0.454 \\
\hline$\tau_{2}(\mu \mathrm{s})$ & 485 & 285 & 143 \\
\hline
\end{tabular}

\section{LSC FUNCTION PARAMETERS FOR THE STAN- DARD IEC 62305-1 LONG STROKE CURRENTS}

In addition to these lightning currents the waveform of a long-term lightning current is also defined in IEC 62305 [1]. NCBC function is defined as an analytically extended function. Based on that, the long-stroke current (LSC) function is proposed as:

$$
i(0, t)= \begin{cases}I_{m}\left[\left(t / t_{m}\right) \exp \left(1-t / t_{m}\right)\right]^{a}, & 0 \leq t \leq t_{m}, \\ I_{m}, & t_{m} \leq t \leq t_{m}+\left(T_{l s c}-T_{r}-T_{d}\right), \\ I_{m}\left[\left(t / t_{m}\right) \exp \left(1-t / t_{m}\right)\right]^{b}, & t_{m}+\left(T_{l s c}-T_{r}-T_{d}\right) \leq t<\infty,\end{cases}
$$

where $T_{l s c}$ is the duration of the long stroke current, $T_{r}$ is the rising time from $0.1 I_{m}$ to the maximum current value, and $T_{d}$ is the decaying time from $I_{m}$ to $0.1 I_{m}$, as in Fig. (15).

Table 2. Parameters of CBC Function for IEC 62305-1 Currents Waveshapes [1]

\begin{tabular}{|c|c|c|c|}
\hline \multicolumn{4}{|c|}{ CBC Function Parameters } \\
\hline & $\begin{array}{c}\text { First } \\
\text { Positive Stroke } \\
\mathbf{1 0 / 3 5 0 \mu \mathbf { s }}\end{array}$ & $\begin{array}{c}\text { First } \\
\text { Negative Stroke } \\
\mathbf{1 / 2 0 0 \mu} \boldsymbol{s}\end{array}$ & $\begin{array}{c}\text { Subsequent } \\
\text { Negative Stroke } \\
\mathbf{0 . 2 5} / 100 \mu \mathbf{s}\end{array}$ \\
\hline \hline \multirow{3}{*}{$(\mathrm{kA})$} & 215.1 (LPL I) & 101.4 (LPL I) & 50.4 (LPL I) \\
& 161.3 (LPLII) & 76.1 (LPL II) & 37.8 (LPL II) \\
& $107.5($ LPLIII-IV) & 50.7 (LPLIII-IV) & 25.2 (LPLIII-IV) \\
\hline$a$ & 20 & 20 & 20 \\
\hline$b$ & 0.0665 & 0.0096 & 0.00467 \\
\hline$t_{m}(\mu \mathrm{s})$ & 26 & 2.6 & 0.65 \\
\hline
\end{tabular}

Parameter $a$ can be chosen according to the desired waveshape in the rising part, and $b$ according to the decaying part, but current steepness is not specified in IEC 62305-1, where $T_{r}$ is chosen equal to $T_{d}$. Physically more realistic case is that $T_{r}<T_{d}$, which may be easily achieved in the case of using LSC function. $T_{l s c}$ can be also chosen much greater than $T_{r}$ and $T_{d}$.

As an example, parameters of LSC function are chosen as $a=10, b=400, t_{m}=0.8 \mathrm{~s}$ and $T_{l s}-T_{r}-T_{d}=3.4 \mathrm{~s}$ to represent the long stroke current waveshape from [1]. This function is presented in Fig. (15).

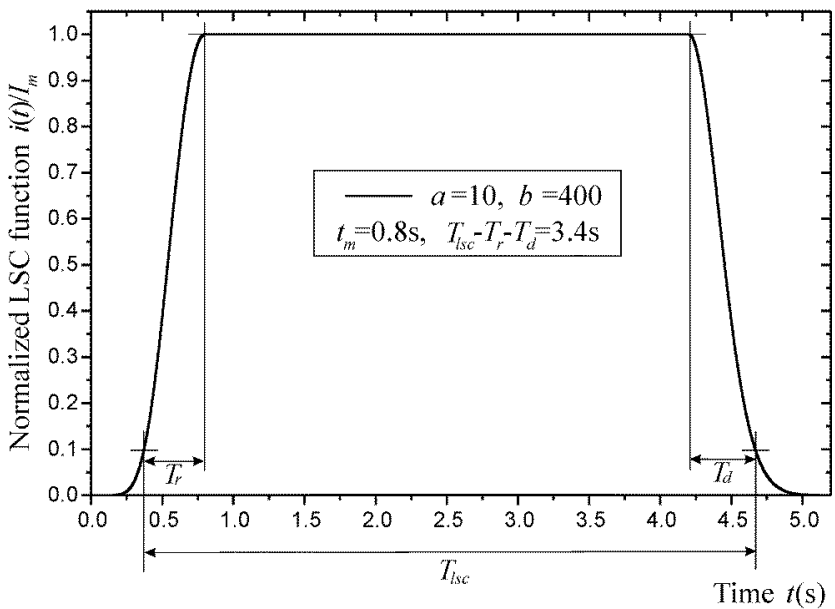

Fig. (15). Normalized long stroke current function.

\section{TRF FUNCTION FOR APPROXIMATING EXPERIMENTALLY MEASURED FIRST STROKE CURRENTS}

In experimental results for lightning currents it can be noticed that rising parts sometimes do not increase continuously, but in two or more distinct rise portions. This is characteristic especially for the first negative stroke channel-base currents. In order to have two rise portions in the front of a current waveshape, the analytical expression for the two-rise function (TRF), based on NCBC function, is proposed in [21] as the following: 


$$
i(t)= \begin{cases}I_{m 1} \sum_{i=1}^{m} d_{i}\left[\frac{t}{t_{m 1}} \exp \left(1-\frac{t}{t_{m 1}}\right)\right]^{a_{i}}, & 0 \leq t \leq t_{m 1}, \\ I_{m 1}+I_{m 2} \sum_{i=1}^{l} f_{i}\left[\frac{t-t_{m 1}}{t_{m 2}-t_{m 1}} \exp \left(1-\frac{t-t_{m 1}}{t_{m 2}-t_{m 1}}\right)\right]^{b_{i}} & t_{m 1} \leq t \leq t_{m 2}, \\ \left(I_{m 1}+I_{m 2}\right) \sum_{i=1}^{n} g_{i}\left[\frac{t}{t_{m 2}} \exp \left(1-\frac{t}{t_{m 2}}\right)\right]^{c_{i}}, & t_{m 2} \leq t<\infty,\end{cases}
$$

where $a_{i}, b_{i}, c_{i}$ are parameters, and $d_{i}, f_{i}, g_{i}$ are weighting coefficients, so that:

$$
\sum_{1}^{m} d_{i}=\sum_{1}^{l} f_{i}=\sum_{1}^{n} g_{i}=1 \text {. }
$$

In (9), $m$ and $l$ are chosen numbers of terms for the rising parts, $n$ for the decaying part of the function, $t_{m 1}$ is the risetime to the current value $I_{m 1}$, and $t_{m 2}$ the rise-time to the maximum current value $I_{m}=I_{m 1}+I_{m 2}$.

An example of assumed double-peaked waveshape is given in [22] and a linear combination of two Heidler's functions is used to represent it. As it performs the two-rise front in the current waveshape, it is taken here as the goal function denoted with the dash line in Fig. (16), with parameters from [22]. For TRF is enough to take $m=n=2$ and $l=1$ in this case. The values chosen in advance according to the waveshape from [22] are $I_{m 1}, I_{m 2}, t_{m 1}$ and $t_{m 2}$. Other parameters are obtained by minimizing the error using the least squares method, and are given in the first column of the Table 3.

It should be noted that the approximation is done for the first $10 \mu \mathrm{s}$, as given in [22]. If the approximation is needed in a longer time interval and for the same two Heidler's functions in $100 \mu \mathrm{s}$ or more, then just parameters for the decaying part are different. Longer time interval approximations are also presented in this paper based on experimental results for the first negative stroke currents.

For the first stroke currents measured at Mount San Salvatore (MSS_FST\#2peaks) [23] and at Morro do Cachimbo station (MCS_FST\#2peaks) [24], and for their median characteristics, there is a function proposed in [25] to represent a two-rise front of the current waveshape. While two Heidler's functions are usually required to obtain a subsequent stroke channel-base current having a singlepeaked waveform, some seven Heidler's functions are necessary to obtain the measured negative first stroke current having double-peaked waveform, as claimed in [25]. This expression was used for calculating lightning induced overvoltages at power transmission lines [26]. TRF presented in this paper is used for approximating experimental results for the first stroke currents from [23] and [24], but it can be used also for other similar waveshapes.

The sum of seven Heidler's functions is used in [25] to approximate MSS_FST\#2peaks with parameters as in Table 4, and MCS_FST\#2 peaks with parameters given in Table 5. Its analytical expression is:

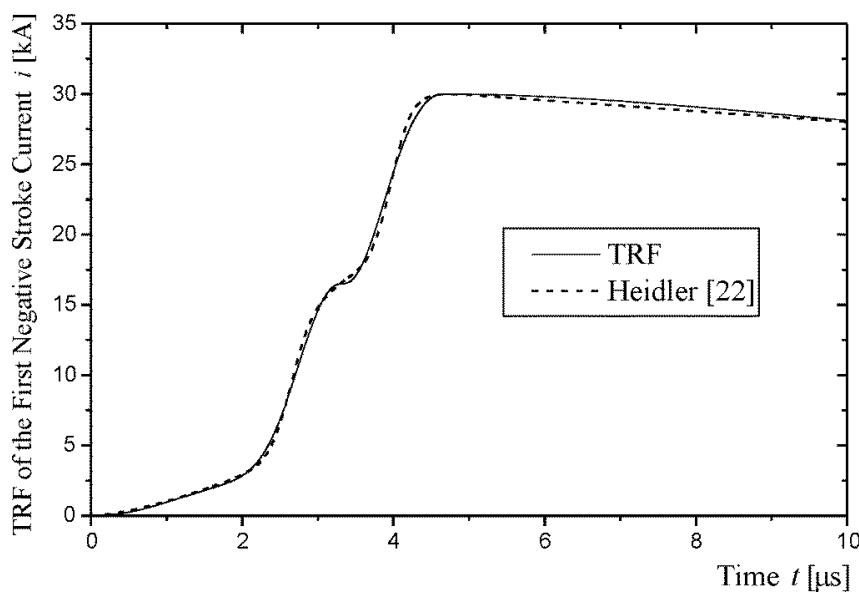

Fig. (16). TRF function approximating the two-rise front waveshape of the assumed first negative stroke current [22].

$i(t)=\sum_{k=1}^{7} \frac{I_{0 k}}{\eta_{k}} \frac{\left(t / \tau_{1 k}\right)^{n_{k}}}{1+\left(t / \tau_{1 k}\right)^{n_{k}}} \exp \left(-t / \tau_{2 k}\right)$,

with $\eta_{k}$ the peak correction factor for $k=1, \ldots, 7$, calculated as:

$\eta_{k}=\exp \left[-\left(\frac{\tau_{1 k}}{\tau_{2 k}}\right) \sqrt[n_{k}]{\frac{n_{k} \tau_{2 k}}{\tau_{1 k}}}\right]$.

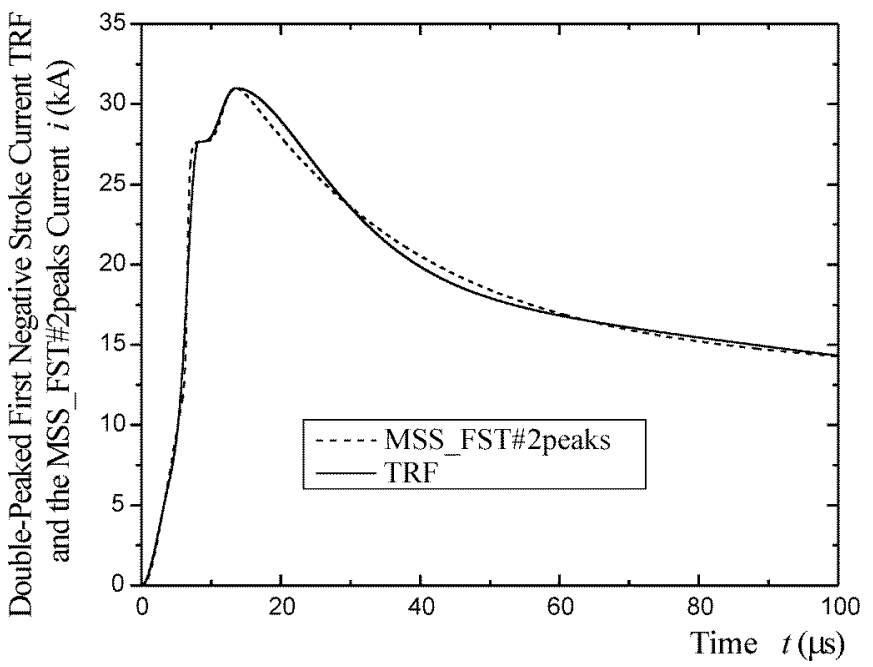

Fig. (17). TRF function approximating the first negative stroke current MSS_FST\#2peaks [23].

Function (11) is taken as the goal function to be approximated with TRF function (9). The values of $I_{m 1}, I_{m 2}$, $t_{m 1}$ and $t_{m 2}$ are taken in advance to the approximation procedure and determined as values of the function given with (11) for MSS_FST\#2peaks and MCS_FST\#2peaks in their characteristic points. Other parameters are optimized using the least squares method.

The comparison of TRF with MSS_FST\#2peaks is presented in Fig. (17), and with MCS_FST\#2peaks in Fig. (18). Parameters of TRF function approximating these two current functions are given in the second and the third column of the Table 3 . 


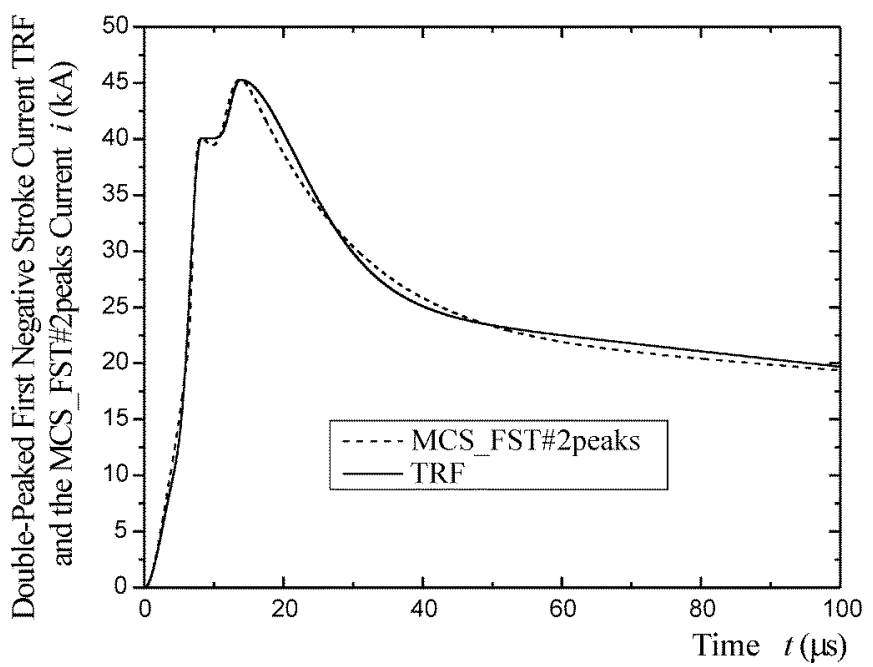

Fig. (18). The TRF function approximating the first negative stroke current MCS_FST\#2peaks [24].

For representing [23] and [24] with seven Heidler's functions 28 parameters are used in [25], and just 11 parameters for the TRF function (9) are enough, if (10) is taken into account.

Table 3. Parameters of TRF Function Approximating First Negative Stroke Currents: An Assumed Two-Rise Waveshape [22], Measured MSS_FST\#2peaks [23] and Measured MCS_FST\#2peaks [24]

\begin{tabular}{|c|c|c|c|}
\hline \multicolumn{5}{|c|}{ TRF Function Parameters } \\
\hline & $\begin{array}{c}\text { Approximating } \\
{[22]}\end{array}$ & $\begin{array}{c}\text { Approximating } \\
{[23]}\end{array}$ & $\begin{array}{c}\text { Approximating } \\
{[24]}\end{array}$ \\
\hline \hline$I_{m 1}(\mathrm{kA})$ & 16.5 & 27.66 & 40.07 \\
\hline$I_{m 2}(\mathrm{kA})$ & 13.5 & 3.34 & 5.215 \\
\hline$t_{m 1}(\mu \mathrm{s})$ & 3.3 & 8.2 & 8.2 \\
\hline$t_{m 2}(\mu \mathrm{s})$ & 4.653 & 13.6 & 13.8 \\
\hline$d_{1}$ & 0.2 & 0.37 & 0.37 \\
\hline$d_{2}=1-d_{1}$ & 0.8 & 0.63 & 0.63 \\
\hline$a_{1}$ & 2.5 & 2.2 & 2.2 \\
\hline$a_{2}$ & 35 & 28 & 28 \\
\hline$f_{1}$ & 1 & 1 & 1 \\
\hline$b_{1}$ & 3 & 5.5 & 15 \\
\hline$g_{1}$ & 0.75 & 0.4 & 0.45 \\
\hline$g_{2}=1-g_{1}$ & 0.25 & 0.6 & 0.55 \\
\hline$c_{1}$ & 0.04 & 2 & 3.3 \\
\hline$c_{2}$ & 0.6 & 0.06 & 0.055 \\
\hline
\end{tabular}

The presented procedure has advantage of choosing maximum values of currents peaks and adequate time intervals in advance. This is important as achieving these characteristic parameters is taken in [25] as the main criterion of the quality of the approximation.

Better approximations could be obtained if there were more terms in (9) than here selected five terms $(m+l+n=5)$, but the aim of proposing TRF was to use simple function as possible, still able to reproduce the desired waveshapes. Besides that, the possibility to obtain analytically TRF function derivative, integral, integral of the square of that function, and its Fourier transform makes it useful for calculations in both time and frequency domain.

Table 4. Parameters of the Sum of Seven Heidler's Functions Approximating Measured Results at Mount San Salvatore [23] for the First Negative Stroke Currents (MSS_FST\#2peaks). Adapted from [25]

\begin{tabular}{|c|c|c|c|c|}
\hline \multirow{3}{*}{$\boldsymbol{k}$} & \multicolumn{5}{|c|}{$\begin{array}{c}\text { Parameters of the Sum of Seven Heidler's Functions } \\
\text { Approximating MSS_FST\#2 peaks [23] }\end{array}$} \\
\cline { 2 - 5 } & $\boldsymbol{I}_{\boldsymbol{k}}(\mathbf{k A})$ & $\boldsymbol{n}_{\boldsymbol{k}}$ & $\boldsymbol{\tau}_{\mathbf{1} \boldsymbol{k}}(\boldsymbol{\mu} \mathbf{s})$ & $\boldsymbol{\tau}_{\boldsymbol{2} \boldsymbol{k}}(\boldsymbol{\mu} \mathbf{s})$ \\
\hline \hline 1 & 3 & 2 & 3 & 76 \\
\hline 2 & 4.5 & 3 & 3.5 & 25 \\
\hline 3 & 3 & 5 & 5.2 & 20 \\
\hline 4 & 3.8 & 7 & 6 & 60 \\
\hline 5 & 13.6 & 44 & 6.6 & 60 \\
\hline 6 & 11 & 2 & 100 & 600 \\
\hline 7 & 5.7 & 15 & 11.7 & 48.5 \\
\hline
\end{tabular}

Table 5. Parameters of the Sum of Seven Heidler's Functions Approximating Measured Results at Morro do Cachimbo Station [24] for the First Negative Stroke Currents (MCS_FST\#2peaks). Adapted from [25]

\begin{tabular}{|c|c|c|c|c|}
\hline \multirow{3}{*}{$\boldsymbol{k}$} & \multicolumn{5}{|c|}{$\begin{array}{c}\text { Parameters of the Sum of Seven Heidler's Functions } \\
\text { Approximating MCS_FST\#2peaks [24] }\end{array}$} \\
\cline { 2 - 5 } & $\boldsymbol{I}_{\boldsymbol{k}}(\mathbf{k A})$ & $\boldsymbol{n}_{\boldsymbol{k}}$ & $\boldsymbol{\tau}_{\mathbf{1} \boldsymbol{k}}(\boldsymbol{\mu} \mathbf{s})$ & $\boldsymbol{\tau}_{\boldsymbol{2} \boldsymbol{k}}(\boldsymbol{\mu} \mathbf{s})$ \\
\hline \hline 1 & 6 & 2 & 3 & 76 \\
\hline 2 & 5 & 3 & 3.5 & 10 \\
\hline 3 & 5 & 5 & 4.8 & 30 \\
\hline 4 & 8 & 9 & 6 & 26 \\
\hline 5 & 16.5 & 30 & 7 & 23.2 \\
\hline 6 & 17 & 2 & 70 & 200 \\
\hline 7 & 12 & 14 & 12 & 26 \\
\hline
\end{tabular}

Other functions having more than two peaks can be approximated using linear combination of the same basic functions, similar to (9).

\section{CONCLUSION}

New functions for approximating various measured or assumed typical lightning currents waveshapes are presented in this paper. NCBC function and the influence of parameters on its waveshape are presented, so as analytical expressions of the function derivative, integral, integral of the square of the function, and its Fourier transform.

Parameters of the proposed functions for representing the first stroke currents, subsequent stroke currents, and long 
stroke currents from the standard IEC 62305-1 are calculated.

The procedure to choose parameters of the proposed functions is simple and gives results which are in excellent agreement with the results of other current functions from literature.

Double-peaked waveshapes typical for experimentally measured natural first stroke currents are approximated using the two-rise front current function. The number of parameters to be calculated is much smaller than for other functions used in literature.

The proposed functions can also represent various pulse quantities in other fields of interest.

\section{ACKNOWLEDGEMENT}

This paper is supported by Project Grant III44004 (20112014) financed by Ministry of Education and Science, Republic of Serbia.

\section{REFERENCES}

[1] IEC 62305-1, Protection against lightning - Part I: General principles, CIEC standard, 2006.

[2] Berger K, Anderson RB, Kroninger H. Parameters of lightning flashes. Electra 1975; 80: 23-37.

[3] Lin YT, Uman MA, Tiller JA, et al. Characterization of lightning return stroke electric and magnetic fields from simultaneous twostation measurements. J Geophys Res 1979; 84: 6307-14.

[4] Heidler F. Travelling current source model for LEMP calculation.: In Proc. $6^{\text {th }}$ Int Zurich Symp; EMC, Zurich, Switzerland 1985; pp. $157-62$.

[5] Heidler F, Zischank W, Flisowski Z, Bouquegnau CH, Mazzetti C. Parameters of lightning current given in IEC 62305 - background, experience and outlook: In: CD Proc $29^{\text {th }}$ Int Conf Ligh Protect ICLP. Uppsala, Sweden 2008.

[6] Bewley LV. Traveling waves due to lightning. AIEEE Trans 1929; 48:1050-64.

[7] Golde RH. Lightning currents and related parameters. Lightning, Physics of Lightning," Golde RH, Ed. London: Academic Press, 1977; vol. 1: pp. 309-50.

[8] Nucci CA, Rachidi F. Experimental validation of a modification to the transmission line model for LEMP calculations: In Proc of $8^{\text {th }}$ Int Zurich Symp; EMC, Zurich, Switzerland 1989.

[9] Nucci CA, Diendorfer G, Uman MA, Rachidi F, Ianoz M, Mazzetti C. Lightning return stroke current models with specified channel base current: a review and comparison. J Geophys Res 1990; 95(D12): 20395-408.
[10] Rakov VA, Uman MA. Review and evaluation of lightning return stroke models including some aspects of their application. IEEE Trans Electromagn Compat 1998; 40(4): 403-26.

[11] Diendorfer G, Uman MA. An improved return stroke model with specified channel-base current. J Geophys Res 1990; 95: 13621-44.

[12] Feizhou Z, Shange L. A new function to represent the lightning return-stroke currents. IEEE Trans Electromagn Compat 2002; 44(4): 595-7.

[13] Javor V. Approximating decaying part of the lightning return stroke channel-base current: In Proc of Abstracts $3^{\text {rd }}$ Int Symp on Lightning Physics and Effects. Vienna, Austria. Apr 2008; p. 26.

[14] Javor V, Rancic PD. A channel-base current function for lightning return stroke modeling. In IEEE Trans Electromagn Compat 2011; 53(1): 245-9.

[15] Javor V, Rancic PD. Application of one suitable lightning returnstroke current model: In Pro Full Papers; Int Symp.Electromagn Compat EMC Europe 2006. Barcelona, Spain. Sep 2006; pp. 941-6.

[16] Javor V. Fourier transform of the pulse function for application in high voltage technique: In Proc $12^{\text {th }}$ Int Conf on Optimization of Electrical and Electronic Equipment OPTIM 2010. Brasov, Romania, May 2010; pp. 89-94.

[17] Shoory A, Moini R, Sadeghi H, Rakov VA. Analysis of lightningradiated electromagnetic fields in the vicinity of lossy ground. In IEEE Trans Electromagn Compat 2005; 47(1):131-45.

[18] Javor V, Rancic PD. Electromagnetic field in the vicinity of lightning protection rod at a lossy ground. IEEE Trans Electromagn Compat 2009; 51(2):320-30.

[19] Javor V. New functions for representing IEC 62305 standard lightning currents: In USB Proc of Papers; $30^{\text {th }}$ Int Conf on Lightning Protection ICLP 2010. Cagliari, Italy, Sep. 2010; paper 1066.

[20] Andreotti A, Falco S, Verolino L. Some integrals involving Heidler's lightning return stroke current expression. Elect Eng 2005; 87(3):121-8

[21] Javor V. Approximation of a lightning channel-base current with a two-rise front: In Proc of Abstracts; $11^{\text {th }}$ Int Workshop on Optimization and Inverse Problems in Electromagnetism OIPE 2010. Sofia, Bulgaria, Sep. 2010; pp. 88-9.

[22] Heidler F, Cvetic J. A class of analytical functions to study the lightning effects associated with the current front. ETEP 2002; 12(2): 141-50.

[23] Anderson RB, Eriksson AJ. Lightning parameters for engineering application. Electra 1980; 69: 65-102.

[24] Visacro S, Soares A Jr, Schroeder MAO, Cherchiglia LCL, Souza VJ. Statistical analysis of lightning current parameters: Measurements at Morro do Cachimbo station. J Geophys Res 2004; 109: D01105.

[25] De Conti A, Visacro S. Analytical Representation of single- and double-peaked lightning current waveforms. IEEE Trans Electromagn Compat 2007; 49(2): 448-51

[26] Silveira FH, De Conti A, Visacro S. Lightning overvoltage due to first strokes considering a realistic current representation. IEEE Trans Electromagn Compat 2010; 52(4): 929-35. 